\title{
Academic Culture and Ethics in the Profession of Teaching, Learning, and Research
}

\author{
R.A.Akindele
}

\begin{abstract}
This article provides deep insights into the nature and dynamics of academic culture in the Nigerian university system. Academic culture is generally conceived as the established tradition, procedure, practices, etiquette, ethics and rules of the game in the conduct of teaching, learning and research. Collectively, these elements provide a conducive environment for the generation/creation, transfer, dissemination and application of knowledge and management of teaching and research industry in support of sustainable development. Consequently, this article posits that the building of academic culture to promote, achieve and sustain the realization of the mission of any university is a huge task, even if scarcity of resources does not constitute too tight a limiting handicap. It is only a mature academic environment, nourished and fertilized inter alia by ethical foundations, democratic and good governance, and conventions and practices that can give birth to a healthy teaching and research culture, sustain and protect it from every form of degradation. For this to be possible, such a mature academic culture has to venerate and choose the life-style of commitment, particularly to the following: scholarship and knowledge; objectivity and truth; tolerance and character building; criticism and dissent; staff-students cooperation and collegiality, all of which are in the service of development.
\end{abstract}

Key words: Research, Knowledge Development, Development, Governance, Culture, Ethics and Character

\section{Introduction}

Scientific research, the cutting edge of knowledge and development, has always had to cope with the joy and anguish of its exponential growth and development, particularly since the beginning of the $20^{\text {th }}$ century. Unquestionably the most reliable and dependable source of knowledge, and indeed a highly priced intellectual commodity in the marketplace of social, economic and technological development, it empowers and sustains human ability to understand and solve problems. It accomplishes this through both its combustible engine of ideas and the sagacious application of its findings which are crucially associated with the building of knowledge. Again, unquestionably, knowledge is power. Although the cliche that knowledge itself is power quite understandably attracts and commands credibility in academic and policy circles, it calls 
for a footnote of clarification, particularly around the hardly contestable assertion that development in any society has become knowledge-incubated, knowledge-inspired, knowledge-activated, knowledge-anchored and knowledge-sustained. The seed of knowledge, planted and cultivated on any fertilized academic learning field, is bound to germinate luxuriantly, beginning in fact from the family, the smallest unit of social organization and the starting nursery-theatre for the informal inculcation of knowledge to young children. But arguably the most prestigious and productive centre of excellence for the cultivation, germination and production of knowledge is the university, a community of students and scholars engaged in teaching, learning and research for the expansion of the horizon and frontiers of knowledge. Euphemistically called the 'ivory tower' in contemporary academic parlance, it is where the following $\bullet$ three key activities that define and encapsulate the mandate of higher education, namely knowledge generation, knowledge dissemination and knowledge application - are largely carried out (Oloyede, 2010:3-5). These activities are traditionally collapsed and; synthesized all over the world under the rubric of teaching and research which certainly constitute the most important preoccupation of all academic staff in any university and country.

Architectured, developed and operating in a world without borders', academic culture is generally conceived as the established tradition, procedure, practices, etiquette, ethics and rules of the game in the conduct of teaching, learning and research. Collectively, all: these elements provide a conducive environment for the generation/creation, transfer, dissemination and application of knowledge and management of teaching and research " industry in the increasingly complex and competitive marketplace of ideas and innovation in support of sustainable development. Perhaps more importantly, they provide a justification for putting an expansive construction on the concept of academic culture in order to enable it capture a number of important preoccupations ancillary to $\mathrm{j}$ it. To view academic culture in its broad universal context, as it should preferably be, conceived, is not to deny that it has relevantly functional specificities in particular: regions or countries which add colour and local character to it, and, in so doing, further enrich and strengthen the overriding global architecture of customs, practices and processes in the conduct of the academic enterprise of teaching, learning and research.

An examination of academic culture that has developed in the profession of teaching and research in the university system can be anchored to and explained within the ${ }^{u}$ context of a three-concentric-circles paradigm (Gambari, 1989:21). Together, all the three circles therein not only contribute immensely to the impregnable fortification and consolidation of key aspects of the culture and its environments but also, individually, highlight its uniqueness. The paradigmatic model assigns to the first innermost circle responsibility for overseeing, supervising and maintaining the sanctity and integrity of the system's academic culture and the duty of preserving its golden norms, etiquette, ethics, commandments, collegiality, openness and mentorship. All of them are glued together by the vibrant digital cobwebs located in the hallowed academic shrine, which not only provides a good environment but also makes a strong case for the triumph of 
truth, objectivity, freedom, choice, criticism, dissent, tenure, mentorship and tolerance. This circle commands and deserves a more elaborate attention later, as it constitutes the central preoccupation of this essay.

The second circle in the three-concentric-circles paradigm broadly draws attention to and projects the view that the university - public or private - may have emerged as an autonomous institution in any country, it is essentially and fundamentally a shared-seed, a shared-vision and a shared-mission in the interconnected landscape of global scholarship. And to this extent, it wears a common academic gown (regalia) and, of necessity, imbibes the culture of global practices seemingly compelled by the fact of interconnectivity in the global village that has emerged. It is true that any university which wants to earn a good name for itself must seek to navigate through both the water of its immediate [national/domestic] environment and the wider ocean of its larger [international/external] environment in its search for academic visibility and excellence. But it needs to remind itself constantly that, ideally, its teaching and research "must be morally and intellectually independent of all political authority and economic power" (Oloyede, 2010:9), if it does not wish to remain and operate in the constrained shadows of its preposterous and artificial independence in the present-day world without borders. This is not to say that research today must seek to reinvent the wheel in its utterly absurd, blind and counterproductive drive towards the maintenance, preservation and demonstration of its autonomy and independence.

The third circle in the analytic paradigm stands for and represents an affirmation of the irreversibility of the long-standing trend towards the unity of knowledge, despite the increasing, indeed amazing, range of specialization in all academic fields of learning. The hare-race towards specialization is clearly a most welcome development which continues to deepen and widen the frontiers of knowledge. The alleged battle of/for comparative and competing importance being waged between the notion of unity of knowledge and proliferation of specialized knowledge will seem to have paled into insignificance and has been thrown into the dustbin of irrelevance and anachronism largely by the most welcomed and increasing worldwide adoption of an interdisciplinary and multidisciplinary approach to the conduct of contemporary research and the resulting qualitative improvement in research outcome flowing from and associated with it. In actual fact, in the universe of the knowledge kingdom, both unity and specialization paradoxically complement and strengthen each other.

The primary, though not exclusive, preoccupation in this essay is with how the plethora and diversity of activities taking place in the innermost circle in the three-concentriccircles paradigm collectively shape the character of academic culture. Concentrating therein is also in the firm belief that the circle provides the most appropriate venue for the conduct of those crucial and critical academic activities, particularly the scholarly rituals of teaching, learning and research. Admittedly, academic culture certainly encompasses more than activities involving teaching, learning and research, even though they are generally regarded as the most important components of it. It is also an 
impressive arena of colourful and venerated academic ceremonies, including procession, featuring elegant dress - the gown, hood, tassel and cap - well-soaked in the hallowed shrine of tradition, the social owambe ceremonies in celebration of the joy of appointment to professorship and the delivery of inaugural and valedictory lectures, conduct of matriculation exercise and convocation ceremony, and the 'town-and-gown' relationship built into, and demonstrated by, the award of honorary degrees to distinguished and carefully selected individuals in the community near and far away. Also noteworthy is the task as well as the challenge of character-building which dresses up and enthrones the culture with the gorgeous apparel of highly priced and most soughtafter social value called moral education (Oloyede, 2010: 21-24).

Although the last two components of the broad architecture of academic culture have not been the central focus of this essay, they nevertheless deserve mentioning in passing, especially because, in their own right, they constitute and indeed command and deserve a strategic footnote of relevance and importance. This is particularly so of the academic culture of the award of honorary degrees. Honorary degree is a precious and highly prized academic commodity that is and should be awarded and given to only those who deserve it on the basis of their impeccable character, social integrity and demonstrated contribution to the society. The choice of recipients should be made by an academic community of wise and respected men and women wider than what presently is the case, and whose loyalty and commitment to excellence and fair play are unquestionable.

\section{Teaching and Research}

Academic culture in any institutional system of higher education relating to the profession of teaching and research, particularly in the university system, is a product of a long established tradition operationalized and governed by legal rules, conventions and practices. It reflects the uniqueness and peculiarities of the procedures and processes involved in the conduct and management of knowledge generation, knowledge dissemination and knowledge application within the context of clearly established norms, regulations, conventions and ethics. Perhaps most importantly, academic culture is informed and enriched by the wisdom and imperative of institutionalizing and, consequently, highlighting respect for some fundamental principles and dogmas in the enterprise of teaching and research.

The starting point in any discussion and analysis of academic culture is the explication of the relationship between teaching and research. Succinctly put, even though both are analytically and conceptually distinct components of the academic enterprise, they are practically interrelated since neither of them can be meaningfully discussed independently of the other in any higher education regime, particularly in the university system. Furthermore, they are virtually inseparable, being mutually influencing and enriching each other. To this extent, together they congruently help to 'shape the contours, contents and profile of academic culture. Additionally, given the fact that the 
university is an academic community largely and primarily of students and teachers, the academic culture that sustains it must be built on principles and dogmas that protect not only the interests of both groups but also the integrity and sustainability of the academic culture itself. Protecting the interest of both promi lent groups necessarily demands that academic culture must primarily and preponderantly be teacher-focused as well as student-centred.

\section{(a) Teaching and Learning: Students and Teachers}

The beneficiaries of teaching are students in the various academic programmes who seek to acquire knowledge, training and skills in order to earn, in colloquial parlance, a 'meal ticket' in the short term, and, in the long run, to enrich their minds with that knowledge. Without them, technically and philosophically, the university either does not exist or stands castrated, consequently becoming an empty shell of itself. But important as students are as a group, they do not constitute the first pillar actors shaping the contours of the academic culture, even though their representatives are increasingly being symbolically, tokenly and peripherally involved in the management of the university's academic enterprise. And this participation is, of course, largely at the lower levels. Their Union has a government expected not only to be elected through a free, fair and credible election under the watchful eyes of the university's Directorate of Students Affairs but also to be consulted by the university management on issues of direct interest to them, particularly those bearing on their rights, freedom, campus accommodation in hostels and conditions under which they receive knowledge and training on which they are making investment of their time and resources. Sometimes, the Student Union government is peremptorily dissolved and caretaker administration put in place by the central authority in the university. And, once a while, the university is closed down and students sent home to prevent a breakdown of law and order in the wake of what is considered as an irresponsible collective student misbehaviour.

Collectively, teachers/lecturers unquestionably enjoy the status of first pillar actors in the teaching component of the academic enterprise. For those of them who are looking forward to a 'life-long' career in teaching and research, tenure is a much sought-after value and goal. For all full-time staff, it is preceded by confirmation of appointment after two years of certified diligent performance in the academic service. A tenured academic staff cannot easily be removed from office until some carefully laid down procedures and processes laid down in the Staff Conditions of Service have been meticulously followed, with the staff given not only the right of hearing but also of appeal even to a body outside the university, quite understandably under the watchful eyes of the local chapter of the national Academic Staff Union of Universities (ASUU) that seeks to protect the rights and privileges of all academic staff in Nigeria's public sector universities. Apart from professors who now compulsorily retire at the age of 70 years, all other academic staff go on retirement at the age of 65 years (FGN-ASUU Agreement, 2009:19). Given the proliferation of universities in the country today, an 
increasing number of retired academic staff subsequently seek contrgcf appointment renewable usually every two years under a slightly modified Conditions of Service.

Academic culture, particularly in Nigeria where government at both federal and state levels preponderantly fund a large proportion of the expenditure of the university enterprise, cannot ostracize itself from the industrial dynamics of bargaining and imperative of negotiation not only between the government and their universities, which is usually under ASUU's auspices, but also between each university and its ASUU chapter. To argue that such negotiation/bargaining falls within the ambit of governance and administrative culture tells only a partial truth. The greater truth is that the elasticity of academic culture, which gives zero tolerance to anything that affects detrimentally its health and integrity, does suggest that academic enterprise must pay attention to any major activity that has some relevant and crucial bearing on its wider environment and consequently affects it.

Academic culture prescribes for lecturers key roles in the students' learning exercise: painstaking preparation for delivery of lectures to the students, demonstration and confirmation of familiarity with the subject-matter of their courses, demonstrated capacity to articulately communicate their thoughts to their students and availability for and openness to consultation with them. With regard to the building of academic culture in the profession of teaching, the starting point is, without doubt, the acquisition of respectable academic degrees followed by the need to develop competence to prepare and make available to the students a good and robust course outline for each course that accurately reflects the course description as well as to support it with the latest reading materials readily available. Beyond this is the need to ensure that examination questions for the students reflect and cover the broad range of the themes and issues covered during the lecture series for the course. The students' answer-scripts provide the final academic 'meeting-point, and artificial contact' between the students and their lecturers. And here, the golden rule to be followed during this artificial 'contact' period is a combination of fair play, consistency and objectivity in marking the answer-scripts according to the 'marking scheme' already prepared. The teacher is a 'judge' who, on the basis of the answer-scripts before him, determines whether his/her students pass or fail; he/she, occasionally, may not be the final judge because the answer-scripts of undergraduate students in their final year require moderation by some other academic judges, usually from outside the university. Similarly, the dissertation and thesis produced by candidates for the Master of Science (MSc) and Doctor of Philosophy (PhD) degrees respectively are examined by reputable scholars outside the university in the appropriate academic field in order to confer a stamp of credibility and excellence on them. Perhaps more importantly, the existing academic culture reserves to the students the right of protest and appeal against a lecturer's evaluation of their performance in a written examination. This right is supposed to be exercised in accordance with some due process prescribed for it. However, the greater truth is that, given the esprit de corps among academic staff, to say that the chances of a successful protest and appeal are difficult is not to admit that they are absolutely impossible. A 
student's formal protest against his teacher's evaluation of the former's performance in written examination should neither be discouraged nor trivialized, as it adds value to the integrity, openness, transparency and impartiality of the academic culture.

With respect to learning and determination of students' performance in course work, academic culture has moved away from exclusive preoccupation with and reliance on the regime and practice of final written examination as the sole method of assessment. Attention is increasingly also being given to continuous assessment of students through the conduct of tests and assignment of term papers on relevant topics for preparation and presentation during each semester. As a complementary supplement, continuous assessment usually carries some mark value of up to $30 \%$ of the total mark value for each course. This, in effect, means that the end of semester examination will carry only $70 \%$ of the total mark value for each course. Together, both of them provide a better mode of assessment than each of them separately. It is for this reason that each lecturer should be mandatorily required to deposit with his head of department, who is the chief examiner, evidence that the former has fulfilled the requirement for continuous assessment of his students in each of the courses taught and examined.

Of crucial and relevant interest, indeed a great concern, to the community of teachers in an institution like Nasarawa State University, Keffi (NSUK) is the perceived peripheralization and seeming irrelevance or, at best, gross undervaluation, of teaching in the structure and process of assessment of their performance at the-end of every academic year. The truth, which needs to be told, is that, until two practices are put in place, academic culture built around teaching will continue not only to suffer from the internal crisis of undervaluation but also to cry increasingly louder for a more robust attention to an upward valuation. Deaf ears cannot be turned to this complaint. One practice is to review upward the value assigned to teaching in the scale of assessment for promotion, a task which recently received some palliative and half-hearted attention at the NSUK. The other is to device a practical method of assessing each lecturer's quality of teaching by both the head of department and the students themselves. Admittedly, the task of student assessment of their lecturers' teaching ability will not be easy; but that is not to deny that a procedure for working it out and putting it in place can be designed and implemented. In any case, it is already in practice in many other universities both nationally and internationally.

\section{(b) Research and Knowledge Generation}

As earlier pointed out, knowledge generation is central to the preoccupation of all academic staff in the university system. Advancement of the frontiers of knowledge is through the conduct of theoretical and applied research in all areas of human endeavour. A vigorous war of words and experiments on the battlefield of facts, research itself has, of course, also been in the service of teaching, in addition to being the engine of growth in the academic enterprise of knowledge creation. All of these arguably underscore and explain why it is given the pride of place in the structure and process of annual 
evaluation and assessment of any university's academic staff. The popular hackneyed phrase -publish or perish - is an epitaph usually inscribed on the open shield of honour in celebration of academic culture's concern with excellence in the university system, and especially to remind every lecturer that publication stands prominently on the roadmap and opens the thoroughfare to promotion and academic advancement.

The conduct of research sits firmly on some ethical foundation and governance imperatives partly in a determined effort to purge university's academic culture of some of its debilitating ills and to install or strengthen its golden norms, commandments, etiquettes, openness, mentorship, constructive criticism, tolerance and dissent traditionally associated with academic work. Arguably the most detestable sin in the academic kingdom is plagiarism, which is corruption of academic culture and a monumental intellectual fraud in academic life. Simply and succinctly defined, it is the taking and using of another person's thoughts, writings or intentions as one's own. In academic circles, a plagiarist is a 'kidnapper' who steals another person's intellectual property without acknowledging its source and falsely claiming ownership of the writing and selling it. Plagiarism, in the body language of scholarship, is an academic haemorrhage, a degradation, strangulation and perversion of academic culture that can easily transform the well-respected academic shrine, in which all scholars worship, with pride, in the marketplace of ideas, into a wretched cesspool of academic iniquity and fraud. Also involved in this academic sin are students who merely edit research projects, already submitted elsewhere to other universities by other students and fraudulently submit them in partial fulfillment of the requirements for the award of their own diplomas and degrees in their own universities. The university does more than frown at such behaviour; it condemns plagiarism in the strongest possible terms and imposes severe punishment on the academic crime not just according to the specific rules and prescription of punishment by each university but in accordance with the common code of punishment in the wider profession of teaching and research all over the world.

Other academic sins exist in the system, among which is examination malpractice/ misconduct which has been rather difficult to stamp out either because of the sophistication with which it is being perpetrated by the students and perhaps with the connivance of invigilation-support staff or because the punishment it attracts does not have sufficient and weighty deterrence value.

Yet another academic sin that conspicuously lacks moral integrity is the increasing and unethical prostitution of the relationship between students and lecturers, particularly between female students and their male lecturers. Ordinarily, the ethics of the relationship between female students and their male lecturers should correctly be grounded on strict rules of decent behaviour in the academic marketplace of teaching and learning, and of trust and mutual respect. The correct ethics is contaminated and soiled when considerations other than competence and quality of work are allowed to influence and determine the value of marks awarded to not only lazy female students 
who are prepared to pay any price, including the sale of their body and honour in order to escape the ridicule and pains of failure, but also to academically weak but wealthy male students who quietly but suspiciously flaunt their wealth and position and use them as instruments for an unsung, silent, gentle and surreptitious intimidation of their lecturers who, in the latter's materialistic interest, are tempted to welcome rather than resist it in order for those students to achieve underserved success in the courses taught and examined by those lecturers. Such prostitution in the academic system by both the teacher and the student, the 'seller' and the 'buyer', or the 'demander' and the 'giver' in the obnoxious give-and-take relationship offends and morally pollutes the ethics and virginity that academic culture ought to preciously parade with dignity. There are, of course, some students who, caught up and baptized in the philanthropic web of altruism, are not willing to wait until they graduate and become alumni and alumnae before demonstrating their gratitude to the institution that will become their alma mater. Such students, who voluntarily offer assistance to their departments and faculties, do not prostitute their 'gift' to the latter, and can be given the benefit of the doubt about the sincerity and integrity that animated and underscored their 'support' during their student days. But, in any case, there is no doubt that the line between altruism and self-interest may be thin and sometimes difficult to draw. The greater truth is that the line exists.

Succinctly summarized, the ethical compass stationed on the academic landscape of teaching and research and steadfastly pointing to the right direction of intellectual morality and particularly to the correct lane/track of civilized behaviour provides the best guide and pilot to, and should be followed by, both students and lecturers in an effort to strengthen the ethical imperatives of academic culture.

At the heart of the governance imperatives relevantly associated with as well as bearing on academic culture are non-(or minimal) interference by government in the running of the academic enterprise, even when funded by them; democratization and noncentralization of power in the hands of the internal management authorities in the university system; respect for, protection and sustenance of academic freedom as well as the strengthening of the committee system as the operational method for the making of decisions at various levels in the academic community.

Academic culture flaunts its pride and seeks consolidation of its inner strength through reliance on and veneration, indeed romanticization, of the following fundamental values in the academic armoury of scholarship: truth, objectivity, criticism, dissent, accuracy, tolerance and freedom. It is customarily said that in the science of the universe, truth will triumph and survive; that objectivity commands and provokes respect for research findings; that criticism and dissent are functional in so far as they strengthen the digital cobwebs of research in the shrine of scholarship; that a researcher must demonstrate some level of tolerance for the views of others even if and when he is opposed to them; while freedom, though not unlimited, permits a scholar to determine what he wants to 
research upon and how he wants to go about it, of course within the context and limit of reasonableness.

In academic circles, because research plays a central role in knowledge generation, it preponderantly determines the ranking of scholars in the hierarchy of status and position in the profession. At the pinnacle of academic excellence in the global theatre of scholarship, distinguished scholars are annually awarded the Nobel prize in recognition of their exceptional contribution to their field of study and advancement of knowledge therein. At the national level all over the world, professorship is at the top of the academic hierarchy, honoured and venerated. And this explains why the criteria for promotion of academic staff put more weight on evidence of research and quality publications as the most crucial and influencing criterion, particularly for associate and full professorial appointments through external peer review and assessment of candidates' published works.

It certainly does more than this on some other fronts. For instance, it also explains why in many universities in this country and perhaps elsewhere, some social ceremonies have come to be associated with promotion or appointment to professorship. A new professor and his family customarily organize expensive parties and even commission common dresses (aso-ebi) to be worn by themselves and their friends along with beating of drums and dancing, in addition to printing of calendars to honour and celebrate the appointment as well as attending thanksgiving prayers in the church or mosque in celebration of the new academic status. The now seemingly established social custom has become so contagious that a new professor, who does not wish to suffer from the tyranny of this custom and the shame of non-conformity with it will bring to him/her, feels compelled to follow the tradition and organize such flamboyant ceremonies. This social aspect and dimension of the academic culture may well be indigenous and peculiar to only countries in the Third World. Given the sanctity and vibrancy of their value system and the loyalty it commands in those countries, and possibly elsewhere, it is not incongruous to accommodate and welcome into the paraphernalia and cobwebs of academic culture the secondary side-show of colourful social celebrations in the wake of and support for a new professorial appointment. This side-show of entertainment seems to have become an accepted part of academic culture though with some variations across universities and social environment. It resurfaces when professors deliver their inaugural lectures. The institution of inaugural lectures arguably constitutes the climax of the debt which every professor owes to his/her colleagues in the profession of teaching and research. Every professor looks forward eagerly to delivering his/her inaugural lecture and works hard for it as it provides him/her an academic platform to showcase, with pride mixed with humility, his/her academic contribution to scholarship. A university that sidelines or trivializes the institution pf inaugural lectures in its academic culture stabs itself at the back and consequently weakens the spinal cord of its academic nervous system. 
With the advantage of hindsight and historical practice in many universities, particularly in Nigeria, of lesser importance and diminishing attention given to it than to inaugural lecture is the valedictory lecture which a professor should normally be expected to deliver at the end of his/her teaching career. Nevertheless, it is important to stress both the uniqueness of this custom, though presently lackadaisically observed, and the need to make it a vibrant component of the academic culture in Nigeria's university system. On the difference between inaugural and valedictory lectures, it is not sufficient to say that the different descriptive adjectives before both lectures and the timing of delivery of both of them speak for themselves and provide the much-needed answer. The greater truth is that the former is a comprehensive presentation of a professor's research focus and self-assessed contribution to scholarship in his field of teaching and research, while the latter is, to a large extent, a record of an about-to-retire professor's teaching and research experience and services over the years and contribution to the academic community life during his/her years of professional duty in the university system

\section{(c) Teaching and Knowledge Dissemination}

A research scholar disseminates information through teaching of the students and publication of his research findings largely in books and academic journals. Just as academic culture correctly and appropriately pays due attention to the centrality of learning through teaching, it ignores the role of books and journals in information dissemination exercise at its own peril. Academic journals usually constitute the first venue and theatre for the arrival of new scholarly information in virtually all academic disciplines, at least until the recent arrival of the Internet. This explains why the academic and administrative regime for supervising journal publication must be designed and operated within specific guidelines aimed at not just ensuring quality of production and editorial excellence but certainly also, and perhaps more importantly, making room for anonymous peer review of typescripts by outstanding scholars in the relevant fields. Care must, in addition, be taken to ensure that members of any journal's Editorial Board and their friends do not exploit the advantage of their positions for their personal benefit. Peer review, a very important and crucial practice in academic tradition and culture, exists at least in three different but interrelated situations/contexts. First, at the lowest level, when a lecturer finishes the draft of an article or of a book meant for publication, he/she often customarily sends it to a senior colleague in the field of study for his/her comments and advice aimed at improving its quality before submitting it for consideration for publication. This is also partly a manifestation of mentor-mentee relationship. Secondly and similarly, an Editor of any reputable academic journal or a well-established academic publishing outfit, on receiving such a manuscript for publication in a journal or into a book, arranges for its peer review before deciding whether or not to accept it for publication. Thirdly, and perhaps most importantly, the publications of an academic staff seeking promotion or appointment to professorship are peer reviewed usually by three distinguished scholars in the same field of study. Peer review is a quality control mechanism for assuring and promoting academic 
excellence as well as facilitating selection of the best choice of both scholarship and academic leadership in the profession of teaching and research.

\section{The Library as an Academic Institution}

That research has justifiably earned appellation as the spinal cord of knowledge generation and engine of development has had much to do with the avalanche of information created by it for planning purposes. The collection, documentation, preservation and management of such huge information become an integral part of the challenges facing academic culture today. A discussion of that culture that peripheralizes the library, the heartbeat and soul of the academic enterprise of teaching, learning and research, and puts professional librarians at the margin of that culture fails the acid test of reasonableness and rationality. The library has emerged over a long period of time as the traditional institutional centre of information storage and dissemination, although an alternative theatre for accommodating and preserving such information has emerged with the birth of information and communications technology, and the consequent prominence associated with the Internet as a facilitator of scholarship in the world of learning and research. It is preposterous, and indeed the mother-of-all lies to argue that this more recent development will ultimately sideline the library and make it irrelevant as an academic infrastructure.

The truth of the matter is that the library itself welcomes it and is congruently adjusting to it in its practices. Within the purview of academic culture, what is relevant to note is that while scientific research generates information, both the library and the Internet store and disseminate it. It may be true that, as Obama (2014:62) recently and pungently "puts it, "[fjoday... you can hold in your hand more information than the world's greatest libraries" in this age of information and communications technology. Internet is unquestionably an elaborate and an unbelievably magnificent electronic library. Both the physical library and the Internet will appear in the dictionary of academic culture as the two sides of the same information storage coin and data bank. Therefore, that professional librarians are regarded as academic staff requires no elaborate justification, although the use of this nomenclature for them calls for caution as the former are more in the service of the latter in the profession of teaching and research than anything else, even while admitting that both groups recognize and work towards solidifying their mutually reinforcing and complementary functional relations.

\section{Conclusion}

The mission of a typical university like Nasarawa State University, Keffi (NSUK) reads as follows: "To provide and promote qualitative, innovative and stimulating teaching, learning and research environment to enable individuals develop their full potentials for efficient, dedicated and selfless service to the State, the Nation and Humanity" (Mainoma, 2014:3). Building academic culture to promote, achieve and sustain the realization of the mission stated above is a huge task, even if scarcity of resources does 
not constitute too tight a limiting handicap. It is only a mature academic environment, nourished and fertilized by ethical foundations, democratic and good governance, conventions and practices that have stood the test of time, and characterized by reciprocity of interest on the part of both students and teachers and a committee system, which ensures wider participation in decision making, that can give birth to a healthy teaching and research culture, sustain it and protect it from every form of degradation.

With particular reference to the use of the committee system, a recent study of the Obafemi Awolowo University, Ile-Ife came to the conclusion, arguably applicable to all universities in Nigeria and elsewhere, that, whether or not the committee system is incorporated into the university statutes, committees "constitute...[a]...veritable instrument for the running of university administration and... [are]... indeed a necessary part of the institutional life of the university" (Okotoni and Adegbami, 2013:1). However, the point needs to be made that this model of decision-making is not a wholesome assault on the regime of hierarchy and seniority which characterizes the profession of teaching and research, especially as recommendations of any committee can be ignored, sidelined or rejected. In the university system, academic culture venerates and dignifies professorship as the apex of the academic hierarchy, even more so than vicechancellorship, the post of both the Chief Academic and Chief Executive Officer of the University. This explains why being a professor is the ambition of all those who enter into the profession of teaching and research and wish to make it a career. In its operation, the committee system of decision-making cannot ignore the role which academic seniority and experience enable professors to play in shaping the contours of decisions that emerge from the committee system of policy advice and policy making.

Largely concerned with the imperative of enabling the teaching and research environment in the university system to be conducive to academic excellence, the NSUK Mission stated above is unacceptably silent on and consequently ignores completely the role of the university in character building and moral education for all the students passing through its gate. Because ethics is "the study and practice of the kind of life an individual ought to live... the framework of moral character, behaviour and comportment based on societal core values" (Quoted in Smah, 2012:4), it is important for academic culture to concern itself also with the task and challenge of character-building and moral education for its students. It is in this context that one appreciates the extent to which university authorities in virtually all the institutions have gone to put in place a 'dress code' for students on the university campus, particularly in the classrooms and offices, to mount a vigorous campaign against cultism, drug abuse, prostitution, lateness to and absence from lectures, and to prescribe a water-tight regime of sanctions for breach of the rules against them. In the final analysis, character, like education, matters a great deal in the profile of all individuals, including those operating in the academic kingdom of higher education, particularly in the university system. It needs to be borne in mind that the social and moral fibre of any nation is the summation and totality of the moral character of the individuals who live therein, although 
Aristotelian logic/mathematics has it that the whole is more than ${ }^{1}$ the summation of its component parts. In any case, an educated student should also be a 'cultured' student in so far as moral education complements formal academic education, and therefore remains an integral part of the wholesomeness of academic culture.

At least on paper, if not always rigorously in practice, academic culture venerates and eulogizes mentorship and ought to worship it religiously on the grounds that it is an insurance against its collapse, an insurance for its survival, and an insurance for its sustainable consolidation. Succinctly paraphrased as "a reciprocal relation between a mentor, usually a professor and a mentee, a student or a junior colleague, involving emotional transfer of values, attitudes, teaching and learning techniques, and the ethics of the scholarship profession" (Asobie, et al, 2014:6), mentorship cries out loudly and passionately for an 'informal' formalization and a 'tactical' rather than 'strategic' institutionalization largely because mentor-mentee relationship, even though crucial for sustainable survival of academic culture, indeed of the entire academic enterprise itself, should not be forced or imposed on both the mentor and the mentee. Without an emphasis on mentorship role by the senior colleagues, the younger and new entrants into the academic shrine of teaching and research ate likely going to experience some problems of adjustment and adaptation. For them, mentorship facilitates some measure of painless transition into the academic enterprise of teaching and research. Two of the many manifestations of the practice and programmes of mentorship are the pairing of senior and junior colleagues in the teaching of courses and the encouragement of collaboration by senior and junior scholars in the joint-writing and presentation of scholarly articles at conferences and also for publication in academic journals. For reasons of self-interest, academic culture needs to encourage and support investment of more time and attention by the senior colleagues on the practice of mentorship in the university system. The mentees themselves should also demand it in their own selfinterest. There is no doubt that the university, the mentors and the mentees stand to benefit from it.

Finally, against the background of the analysis in the second and third circles of the three-concentric-circles paradigm, it has become clear and incontestable that every nation's academic culture operates within the larger temple of jvorldwide scholarship, featuring openness, practices, competitiveness, transparency and traditions in the presently emerging world without borders. Consequently, if it encourages and facilitates both the functional and built-in mobility of brains and human capital flight across national boundaries and the sharing of common norms, ethics, conventions, practices and challenges, it has to be designed, moulded, configured and operated to enable it capture the vibrant spirit of internationalism and especially of globalization to which it is anchored without, of course, ignoring the specificity of its national environment.

Above all, academic culture inspires, tolerates, extols and emboldens criticism, dissent and activism. As Eayrs (1966:56) elegantly puts it, "[bjefore the intellectual are two life-styles, and two alone. One is the life-style of detachment. The other the life-style of 
commitment. One has to choose." Academic culture venerates and chooses the lifestyle of commitment, particularly to the following: scholarship and knowledge* objectivity and truth; tolerance and character building; criticism and dissent; staffstudents cooperation and collegiality, all of which are in the service of development. This is why the phrase - knowledge, character and development - arguably provides the best and most apt description of the totality of what academic culture stands for and seeks to promote. And, perhaps most importantly, this is also why academic culture $a b$ initio needs to be designed and erected on an effective structure that not only features congruence and complementarity among teaching, learning and research but also sees students and teachers as interdependent components of the enterprise of higher education whose research outcome energizes and sustains multidimensional development in any nation.

\section{References}

Asobie, H. et al, (2014) Interim Report of the Committee on Academic Repositioning and Research Support, Submitted to the Ag. Vice Chancellor, Nasarawa State University, Keffi (NSUK) 23 ${ }^{\text {rd }}$ April.

Eayrs, J. (1966) Right and Wrong in Foreign Policy Toronto: University of Toronto Press.

FGN, 2009. Agreement between the Federal Government of Nigeria (FGN) and the Academic Staff Union of Universities (ASUU)", October.

Gambari, I. (1989) Theory and Reality in Foreign Policy Making: Nigeria after the Second Republic, Atlantic Highlands, New Jersey: Humanities Press International.

Mainoma, M. A. (2014) Vision, Mission and Core Values of Nasarawa State University Reminder, Address of Ag. Vice-Chancellor to Senate on $31^{\text {st }} \mathrm{July}$.

Obama, B. (2014) Text of the United States President Barack Obama's Address to the United Nations General Assembly in New York". Produced in The Nation Thursday, September 25, 2014, p.62

Okotoni, O. and. Adegbami, A.R. (2013) The Use of Committee System and its Challenges in Obafemi Awolowo University, Ile-Ife, The Quarterly Journal of Administration.. Vol. XXXIII, No. 1 [New Series], April, pp. 1-20

Oloyede, I. (2010) Reviving Academic Culture and Etiquette, Paper presented at the $25^{\text {th }}$ AVCNU Conference $19^{\text {th }}-22^{\text {nd }}$ April, held at Osun State University, Oshogbo.

Smah, S. O. (2012) Managing Postgraduate Examinations in Nigerian Universities: Ethical and Governance Imperatives for Effective Programmes Delivery, Paper presented at the Interactive Forum organized by the School of Postgraduate Studies, Nasarawa State University, Keffi (NSUK) on Thursday $8^{\text {th }}$, March. 